\title{
Characteristics and outcomes of nonmelanoma skin cancer (NMSC) in children and young adults
}

\section{Citation}

Khosravi, Hasan. 2017. Characteristics and outcomes of nonmelanoma skin cancer (NMSC) in children and young adults. Doctoral dissertation, Harvard Medical School.

\section{Permanent link}

http://nrs.harvard.edu/urn-3:HUL.InstRepos:40621375

\section{Terms of Use}

This article was downloaded from Harvard University's DASH repository, and is made available under the terms and conditions applicable to Other Posted Material, as set forth at http:// nrs.harvard.edu/urn-3:HUL.InstRepos:dash.current.terms-of-use\#LAA

\section{Share Your Story}

The Harvard community has made this article openly available.

Please share how this access benefits you. Submit a story.

\section{Accessibility}


Scholarly Report submitted in partial fulfillment of the MD Degree at Harvard Medical School

Date: $1 / 4 / 2016$

Student Name: Hasan Khosravi, BS

Scholarly Report Title: Characteristics and outcomes of nonmelanoma skin cancer (NMSC) in children and young adults

Mentor Name and Affiliations: Jennifer T. Huang, MD, Dermatology Program, Division of Allergy and Immunology, Department of Medicine, Boston Children's Hospital

Collaborator: Birgitta Schmidt, Department of Pathology, Boston Children's Hospital 
Characteristics and outcomes of nonmelanoma skin cancer (NMSC) in children and young adults

Hasan Khosravi, Birgitta Schmidt, Jennifer T. Huang

Background: Pediatric and young adult nonmelanoma skin cancer (NMSC) is rare and traditionally associated with predisposing heritable or congenital conditions. Clinical characteristics, outcomes, and iatrogenic risk factors have not been well described.

Purpose: We sought to characterize clinical features, potential risk factors, and gaps in care associated with NMSC in children and young adults.

Methods: This was a retrospective chart review of children and young adults with squamous and basal cell carcinoma.

Results: We identified 28 patients with a total of 182 NMSC tumors. Of patients, $50 \%$ had predisposing conditions, and $46 \%$ had exposure to iatrogenic risk factors of prolonged immunosuppression, radiation therapy, chemotherapy, voriconazole use, or a combination of these. Of patients with iatrogenic risk factors, $62 \%$ developed subsequent cancerous or precancerous skin lesions. No patient was found to have chemotherapy or voriconazole exposure as a sole risk factor. Mean time to diagnosis of NMSC was 948 days with initial misdiagnosis in $36 \%$ of patients. The majority of patients underwent surgical excision.

Limitations: This was a retrospective single institution study with a small number of cases.

Conclusions: Physicians should be aware of risk factors associated with NMSC in children and young adults to provide appropriate counseling and early diagnosis and treatment. 


\section{Contributions:}

My role in this manuscript included: preparation of the IRB protocol for submission, review of 28 patient charts with subsequent documentation in Excel, identification of risk factors for retrospective review, data analysis, initial preparation of the draft detailing the outcomes of our findings, and responding to journal editors. When reviewing the charts, we looked for patients with squamous cell and basal cell carcinomas diagnosed between 1993 and 2014; I recorded demographic data (including Fitzpatrick type, age, ethnicity, and gender), medical history (malignancy, stem-cell or organ transplantation, genetic syndromes), medication history (chemotherapeutic and immunosuppressive agents), radiation exposure (total body irradiation and localized radiation therapy), histopathology records, delays in diagnoses, and modality of treatment. Data analysis that was performed included descriptive analysis, fisher exact test, and unpaired t test. Upon review of the paper by the journal, I also prepared our initial response to each of their concerns and finalized the paper for publication.

My mentor in this project, Dr. Jennifer T. Huang, provided the initial idea for the project and patient database for review. She approved and modified the risk factors and variables that we would evaluate in our review of each patient. In addition, she guided me on the analysis of our findings and edited the paper to effectively relay our results and thoughts to the medical community.

Lastly, our collaborator, Dr. Birgitta Schmidt, reviewed the pathology of each patient's cutaneous malignancy to ensure proper diagnosis.

\section{Link:}

http://www.jaad.org/article/S0190-9622(15)02008-3/abstract

\section{Citation:}

Khosravi H, Schmidt B, Huang JT. Characteristics and outcomes of nonmelanoma skin cancer (NMSC) in children and young adults. J Am Acad Dermatol. 2015;73(5):785-90. 


\title{
Characteristics and outcomes of nonmelanoma skin cancer (NMSC) in children and young adults
}

\author{
Hasan Khosravi, BS, ${ }^{a}$ Birgitta Schmidt, MD, ${ }^{\mathrm{a}, \mathrm{b}}$ and Jennifer T. Huang, MD ${ }^{\mathrm{a}, \mathrm{c}}$ \\ Boston, Massachusetts
}

\begin{abstract}
Background: Pediatric and young adult nonmelanoma skin cancer (NMSC) is rare and traditionally associated with predisposing heritable or congenital conditions. Clinical characteristics, outcomes, and iatrogenic risk factors have not been well described.
\end{abstract}

Objectives: We sought to characterize clinical features, potential risk factors, and gaps in care associated with NMSC in children and young adults.

Methods: This was a retrospective chart review of children and young adults with squamous and basal cell carcinoma.

Results: We identified 28 patients with a total of 182 NMSC tumors. Of patients, 50\% had predisposing conditions, and $46 \%$ had exposure to iatrogenic risk factors of prolonged immunosuppression, radiation therapy, chemotherapy, voriconazole use, or a combination of these. Of patients with iatrogenic risk factors, $62 \%$ developed subsequent cancerous or precancerous skin lesions. No patient was found to have chemotherapy or voriconazole exposure as a sole risk factor. Mean time to diagnosis of NMSC was 948 days with initial misdiagnosis in 36\% of patients. The majority of patients underwent surgical excision.

Limitations: This was a retrospective single institution study with a small number of cases.

Conclusions: Physicians should be aware of risk factors associated with NMSC in children and young adults to provide appropriate counseling and early diagnosis and treatment. ( $\mathrm{J}$ Am Acad Dermatol 2015;73:785-90.)

Key words: basal cell carcinoma; nonmelanoma skin cancer; pediatric dermatology; prolonged immunosuppression; radiation therapy; squamous cell carcinoma.

$\mathrm{N}$ onmelanoma skin cancer (NMSC) is rare in children and young adults. In contrast to adults, where chronic sun exposure is a primary risk factor, NMSC is more often reported in children and young adults with predisposing conditions, including tumor syndromes and photosensitivity disorders. ${ }^{1}$ Prolonged immunosuppression, radiation therapy, and voriconazole therapy are established in the adult literature as iatrogenic risk factors for NMSC but have only been reported anecdotally in children. ${ }^{2-4}$ Given the increasing number of long-term survivors from childhood cancer and other chronic medical conditions, pediatric

From the Harvard Medical School ${ }^{\mathrm{a}}$; and Department of Pathology ${ }^{\mathrm{b}}$ and Dermatology Program, Division of Allergy and Immunology, Department of Medicine, ${ }^{\mathrm{C}}$ Boston Children's Hospital. Funding sources: None.

Conflicts of interest: None declared.

Presented as a poster at the Society for Pediatric Dermatology Annual Meeting in Boston, Massachusetts, July 11, 2015.

Accepted for publication August 3, 2015.

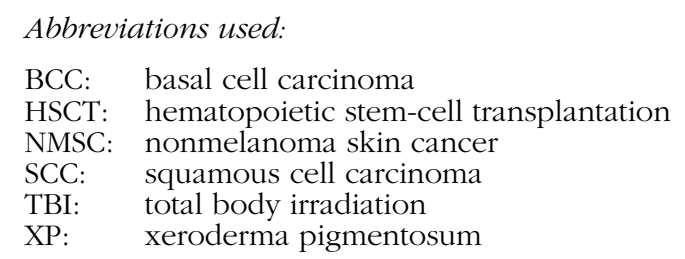

cases of NMSC caused by iatrogenic risk factors may be more common than previously reported. We sought to explore the characteristics of and potential risk factors for NMSC in children and young adults.

Reprint requests: Jennifer T. Huang, MD, Dermatology Program, Boston Children's Hospital, Fegan 6, 300 Longwood Ave, Boston, MA 02115. E-mail: Jennifer.huang@childrens.harvard. edu.

Published online August 28, 2015.

0190-9622/\$36.00

(C) 2015 by the American Academy of Dermatology, Inc.

http://dx.doi.org/10.1016/j.jaad.2015.08.007 


\section{METHODS}

\section{Study design}

This retrospective chart review was approved by the institutional review board at Boston Children's Hospital (P00012932). All patients with a histopathologic diagnosis of squamous cell carcinoma (SCC) and basal cell carcinoma (BCC) between 1993 and 2014 were included. Exclusion criteria included age older than 22 years and patients with insufficient chart documentation. Medical records were reviewed and demographic data were obtained including age at diagnosis, gender, race, and Fitzpatrick skin phototype. Additional data obtained from medical records included medical history (eg, malignancy, stemcell or organ transplantation, genetic syndrome, or other chronic medical condition), medication history (focusing on chemotherapeutic and immunosuppressive agents, and voriconazole), radiation exposure (total body irradiation [TBI] and localized radiation therapy in cGy), and histopathology records.

\section{Study definitions}

Actinic keratosis was defined as basal layer atypia of keratinocytes with maturation, in situ SCC as fullthickness atypia of keratinocytes with lack of maturation, and invasive SCC as full-thickness atypia of keratinocytes with extension into the dermis. BCC was defined as basaloid proliferations including superficial, nodular, cystic, pigmented, and infiltrative subtypes.

Chemotherapy was defined as a medication used for treatment of cancer and excluded agents that were used as part of a transplantation conditioning regimen. Prolonged immunosuppression was defined as immunosuppressive therapy for longer than 6 months.

\section{Statistical analysis}

Descriptive analysis was performed for each variable. Fisher exact test was used for statistical comparisons of categorical variables, and unpaired $t$ test was used for continuous variables. $P$ value less than .05 was considered statistically significant.

\section{RESULTS}

In all, 28 patients and 182 occurrences of NMSC were identified. Of the 28 patients, 7 were given a diagnosis of SCC, 19 of BCC, and 2 of both BCC and SCC. Of 182 NMSC occurrences, 12 were invasive SCC, 25 SCC in situ, and 145 BCC.

\section{Demographics}

Demographic features are described in Table I. Of patients with BCC, $43 \%$ (9 of 21) were younger than 10 years of age. In contrast, only 1 patient with SCC was younger than 10 years of age. Of those with data available, $83 \%$ (19 of 23) were white, and $84 \%$ (16 of 19) had Fitzpatrick skin phototype I or II. There were no significant differences in race or Fitzpatrick type between patients with SCC and BCC $(P=1.0)$.

\section{Risk factors}

Of patients with NMSC, $50 \%$ (14 of 28 ) had predisposing conditions, whereas $46 \%$ (13 of 28 ) had 1 or more iatrogenic risk factors (Table II).

Among patients with BCC, risk factors included nevus sebaceus (6); Gorlin syndrome (6), 3 of whom had received radiation therapy and chemotherapy; history of radiation therapy (1); radiation therapy and chemotherapy (1); TBI, chemotherapy, and hematopoietic stem-cell transplantation (HSCT) (1); and prolonged immunosuppression with 6mercaptopurine for Crohn's disease (1). There were 3 patients with no identifiable risk factors.

Risk factors in patients with only SCC included prolonged immunosuppression in the setting of HSCT complicated by chronic graft-versus-host disease (3), prolonged immunosuppression after kidney transplantation (2), and incontinentia pigmenti (1). In the 3 patients with HSCT who received prolonged immunosuppression, there was an additional history of prolonged voriconazole use (3), liver transplantation (1), lung transplantation (1), TBI (2), and chemotherapy (1). One patient had no identifiable risk factors.

Of the 2 patients with both BCC and SCC, 1 had xeroderma pigmentosum (XP), and the other had prolonged immunosuppression in the setting of HSCT complicated by chronic graft-versus-host disease and double lung transplantation. The latter patient also had a history of prolonged voriconazole use.

Of the 9 patients with NMSC given a diagnosis at less than 10 years of age, 7 had predisposing 
Table I. Demographic features of patients with nonmelanoma skin cancer

\begin{tabular}{|c|c|c|c|}
\hline Characteristic & SCC $=7$ & $\mathrm{BCC}=19$ & Both $=2$ \\
\hline \multicolumn{4}{|l|}{ Sex } \\
\hline Male & $4(57.1)$ & $11(57.9)$ & $2(100)$ \\
\hline Female & $3(42.9)$ & $8(42.1)$ & \\
\hline \multicolumn{4}{|l|}{ Age at diagnosis, y } \\
\hline Mean $( \pm S D)$ & $16( \pm 3)$ & $12( \pm 6)$ & 8 \\
\hline Median (range) & $15(11-20)$ & $12(3-22)$ & $8(2-14)$ \\
\hline \multicolumn{4}{|l|}{ Age group, y } \\
\hline $0-5$ & & $3(15.8)$ & $1(50)$ \\
\hline $6-10$ & & $5(26.3)$ & \\
\hline $11-17$ & $4(57.1)$ & $6(31.6)$ & $1(50)$ \\
\hline$\geq 18$ & $3(42.9)$ & $5(26.3)$ & \\
\hline \multicolumn{4}{|l|}{ Fitzpatrick skin type } \\
\hline I & $2(28.6)$ & $4(21.1)$ & $1(50)$ \\
\hline II & $4(57.1)$ & $5(26.3)$ & \\
\hline \multicolumn{4}{|l|}{ III } \\
\hline IV & & $1(5.3)$ & $1(50)$ \\
\hline \multicolumn{4}{|l|}{$\mathrm{V}$} \\
\hline VI & & $1(5.3)$ & \\
\hline Not charted & $1(14.3)$ & $8(42.1)$ & \\
\hline \multicolumn{4}{|l|}{ Race } \\
\hline White & $6(85.7)$ & $12(63.2)$ & $1(50)$ \\
\hline $\begin{array}{c}\text { Black or African } \\
\text { American }\end{array}$ & & $1(5.3)$ & \\
\hline Hispanic/Latino & & $1(5.3)$ & \\
\hline Asian & & & $1(50)$ \\
\hline Middle-Eastern & & $1(5.3)$ & \\
\hline $\begin{array}{l}\text { Not available/ } \\
\text { declined }\end{array}$ & $1(14.3)$ & $4(21.1)$ & \\
\hline
\end{tabular}

Values are listed as $\mathrm{n}(\%)$ unless otherwise noted.

$B C C$, Basal cell carcinoma; SCC, squamous cell carcinoma.

conditions (5 Gorlin syndrome, 1 nevus sebaceus, 1 $\mathrm{XP})$ and 2 had no risk factors. All patients of nonCaucasian descent or Fitzpatrick skin type III or greater had BCCs associated with predisposing conditions (2 Gorlin syndrome, 1 nevus sebaceus, $1 \mathrm{XP})$.

\section{Iatrogenic risk factors}

In patients with iatrogenic risk factors, 69\% (9 of 13) had 2 or more risk factors. Of those with a single risk factor, 3 received prolonged immunosuppression (2 SCC, 1 BCC), and 1 received localized radiation therapy (1 BCC). There were no patients with chemotherapy or prolonged voriconazole exposure as sole risk factors; all had concomitant prolonged immunosuppression or radiation therapy.

Significantly more patients with SCC than BCC had a history of prolonged immunosuppression ( 5 of 5 vs 1 of $7, P=.015)$. Similarly, there were significantly more patients with SCC alone than BCC alone who had a history of voriconazole use (3 of 5 vs 0 of $7, P=.046$ ).
Of patients who received prolonged immunosuppressive therapy, mean duration of immunosuppression was 3793 days (range 1504-5885). Immunosuppressive agents included systemic corticosteroids (5), cyclosporine (4), tacrolimus (5), sirolimus (1), mycophenolate mofetil (4), intravenous immunoglobulin (2), rituximab (2), 6-mercaptopurine (1), infliximab (1), and azathioprine (1). Of patients who received radiation therapy, 4 received TBI and 4 received localized radiation therapy, with a mean total cumulative dose of 4051 cGy $(n=7$, range 1400-13,375). Of patients who received chemotherapy, chemotherapeutic agents included vincristine (4), cisplatin (3), doxorubicin (3), cyclophosphamide (2), cytarabine (2), etoposide (2), 6-mercaptopurine (1), 13-cis-retinoic acid (1), carboplatin (1), ifosfamide (1), lomustine (1), melphalan (1), methotrexate (1), and mitoxantrone (1).

Among patients with iatrogenic risk factors, $84.6 \%$ (11 of 13) were white, and all had Fitzpatrick skin phototype I or II (if documented). Of the remaining 2 patients, 1 had no available data on race or skin type, and the other was Hispanic/Latino and had Gorlin syndrome.

\section{Risk for subsequent NMSC}

Of all patients with SCC, 78\% (7 of 9) had additional diagnoses of keratoacanthoma or actinic keratosis, and 67\% (6 of 9) had both subsequent SCC and keratoacanthoma or actinic keratosis. Of those with more than 1 SCC, the mean number of subsequent SCCs was 4.7 (range 1-15). Of all 7 patients with subsequent SCC, keratoacanthoma, actinic keratosis, or a combination of these, 5 had prolonged immunosuppression in the setting of HSCT, liver, lung, and/or kidney transplantation; 1 had XP; and 1 had incontinentia pigmenti.

Of patients with BCC, 38\% (8 of 21) developed additional BCCs. Of those with more than 1 BCC, the median number of subsequent BCCs was 2 (range 197). Of these 8 patients, risk factors included Gorlin syndrome (4), underlying nevus sebaceus (1), XP (1), localized radiation therapy (1), and chemotherapy/TBI/HSCT (1).

Of patients with iatrogenic risk factors, $62 \%$ (8 of 13), including all 4 patients with prolonged exposure to voriconazole, had subsequent cancerous or precancerous skin lesions. None of the 4 patients without identifiable risk factors developed subsequent cancerous or precancerous skin lesions.

\section{Diagnosis and management}

The mean number of days from time of lesion onset to diagnosis was 667 for SCC and 1176 for BCC. 
Table II. Clinical features of patients with nonmelanoma skin cancer

\begin{tabular}{|c|c|c|c|}
\hline Characteristic & $\mathrm{SCC}=7$ & $\mathrm{BCC}=19$ & Both $=2$ \\
\hline \multicolumn{4}{|l|}{ Cancerous and precancerous skin lesions } \\
\hline Mean total no. of NMSC (range) & $2.57(1-6)$ & $2.58(1-18)$ & $57.5(17-98)$ \\
\hline 1 & $3(42.9)$ & $12(63.2)$ & 0 \\
\hline $2-3$ & $2(28.6)$ & $3(15.8)$ & 0 \\
\hline$>3$ & $2(28.6)$ & $4(21.1)$ & $2(100)$ \\
\hline Patients with actinic keratosis & $5(71.4)$ & 0 & $2(100)$ \\
\hline Patients with keratoacanthoma & $2(28.6)$ & 0 & $1(50)$ \\
\hline \multicolumn{4}{|l|}{ Clinical history } \\
\hline Predisposing genetic disorder & $1(14.3)$ & $6(31.6)$ & $1(50)$ \\
\hline Underlying nevus sebaceus & 0 & $6(31.6)$ & 0 \\
\hline Prolonged immunosuppressive therapy & $5(71.4)$ & $1(5.3)$ & $1(50)$ \\
\hline Radiation therapy & $2(28.6)$ & $6(31.6)$ & 0 \\
\hline Localized & 0 & 4 & \\
\hline Total body irradiation & 2 & 2 & \\
\hline Chemotherapy & $1(14.3)$ & $5(26.3)$ & $1(50)$ \\
\hline Voriconazole use & $3(42.9)$ & 0 & $1(50)$ \\
\hline Phototherapy & 0 & 0 & 0 \\
\hline Internal malignancy & $3(42.9)$ & $6(31.6)$ & 0 \\
\hline Organ or stem-cell transplantation & $5(71.4)$ & $1(5.3)$ & $1(50)$ \\
\hline Kidney & 2 & 0 & 0 \\
\hline Liver & 1 & 0 & 0 \\
\hline Lung & 1 & 0 & 1 \\
\hline Hematopoietic stem cell & 3 & 1 & 1 \\
\hline cGvHD & $3(42.9)$ & 0 & $1(50)$ \\
\hline Melanoma & 0 & 0 & 0 \\
\hline Atypical nevi & 0 & 0 & $1(50)$ \\
\hline No risk factors & $1(14.3)$ & $3(15.8)$ & 0 \\
\hline
\end{tabular}

Values are listed as $\mathrm{n}(\%)$ unless otherwise noted.

BCC, Basal cell carcinoma; CGvHD, chronic graft-versus-host disease; NMSC, nonmelanoma skin cancer; SCC, squamous cell carcinoma.

Table III. Treatment of nonmelanoma skin cancer

\begin{tabular}{|c|c|c|c|}
\hline Treatment modality & $\begin{array}{c}\text { SCC } \\
\text { invasive }=12 \\
\end{array}$ & $\begin{array}{c}\text { SCC } \\
\text { in situ }=25\end{array}$ & $\mathrm{BCC}=145$ \\
\hline Surgical excision & $5(41.7)$ & $14(56)$ & $133(91.7)$ \\
\hline $\begin{array}{l}\text { Mohs micrographic } \\
\text { surgery }\end{array}$ & $4(33.3)$ & $4(16)$ & $1(0.7)$ \\
\hline Topical chemotherapy & & $5(20)$ & $2(1.4)$ \\
\hline $\begin{array}{l}\text { Electrodessication/ } \\
\text { curettage }\end{array}$ & & & $1(0.7)$ \\
\hline Cryotherapy & & & $1(0.7)$ \\
\hline Not treated & $2(16.7)$ & $2(8)$ & \\
\hline Unknown & $1(8.3)$ & & $7(4.7)$ \\
\hline
\end{tabular}

Values are listed as $\mathrm{n}(\%)$.

$B C C$, Basal cell carcinoma; SCC, squamous cell carcinoma.

Of patients, 36\% (10 of 28) were given a misdiagnosis initially. Initial diagnoses included viral wart and graft-versus-host disease for SCC, and psoriasis, acrochordon, wart, nevus, and atypical nevus for BCC. The majority $(96 \%, 25$ of 26$)$ of patients were ultimately evaluated and given a diagnosis by a pediatric dermatologist; 2 patients had insufficient documentation of follow-up.
Treatment for NMSC largely involved surgical removal, with the majority undergoing surgical excision (Table III). In all, 21.6\% (8 of 37) of patients with SCC and $0.7 \%$ (1 of 148) with BCC underwent Mohs micrographic surgery. One patient with Gorlin syndrome received vismodegib for treatment of remaining BCCs.

One patient with XP developed recurrent BCCs on the face after surgical excision. There were no other reported NMSC recurrences after surgery. No patient developed metastatic NMSC. At the time of publication, 2 patients had died of complications from treatment of noncutaneous, solid tumors; there were no NMSC-associated deaths.

\section{DISCUSSION}

We identified 28 patients with a total of 182 cases of NMSC over a 21-year period, suggesting that NMSC is a rare yet recurrent problem in affected children and young adults. Of patients with SCC, 78\% developed additional SCC, keratoacanthoma, actinic keratosis, or a combination of these. Of patients with BCC, $43 \%$ had additional BCC. 
In our cohort, $46 \%$ of children and young adults with NMSC had iatrogenic risk factors, including prolonged immunosuppression, chemotherapy, radiation exposure, or a combination of these. Of these patients, $62 \%$ had subsequent cancerous or precancerous skin lesions. Prior studies have established an increased risk of NMSC in adult patients after HSCT, organ transplantation, prolonged immunosuppression, chemotherapy, and radiation therapy. ${ }^{5-7}$ Our findings suggest that children and young adults with these exposures, including HSCT, liver, lung, or kidney transplantation, are also at increased risk for NMSC.

Our results confirmed previously reported associations of NMSC with predisposing conditions such as nevus sebaceus, Gorlin syndrome, and XP. ${ }^{1,8-10}$ We had 1 case of SCC arising in a patient with incontinentia pigmenti. In a previous report of this association, the authors postulated that SCC may arise as a result of disruption in the nuclear factor kappa light chain enhancer of activated B cells by mutations in the inhibitor of nuclear factor kappa-B kinase subunit gamma gene, a mechanism that has caused SCC in mouse skin. ${ }^{11}$ We identified an 11year-old child with SCC, and 3 patients aged 9 to 19 years with BCC, who had no identifiable risk factors for NMSC. There have been rare prior reports of pediatric BCC without known risk factors. ${ }^{12-14}$ None of these patients had subsequent cancerous or precancerous skin lesions.

Several trends were noted in the subset of our cohort with iatrogenic risk factors. Patients with SCC were significantly more likely than those with BCC to have a history of prolonged immunosuppression, an association previously observed in adults after solidorgan and stem-cell transplantation. ${ }^{6,7}$ Radiation therapy is established as a risk factor for BCC, with exposure in childhood exponentially increasing BCC risk. ${ }^{5,15}$ Although we found no significant difference in radiation exposure between those with SCC and $\mathrm{BCC}$, this result was likely because of small study size and overlap of risk factors.

The majority of patients had 2 or more iatrogenic risk factors. The absence of NMSC with chemotherapy or voriconazole exposure as sole risk factors suggests that these exposures alone may not be sufficient for the development of NMSC in children and young adults. This finding may be confounded by the common use of these medications in combination with other treatments, as in patients with leukemia who ultimately proceed to HSCT. In contrast to adults, most children have not had sufficient sun exposure to result in NMSC. Thus, the development of NMSC in children and young adults may require multiple factors that contribute to oncogenesis in the skin. Just as chronic ultraviolet exposure has been shown to inactivate tumor suppressor genes, such as protein patched homolog and $\mathrm{p} 53$, via a double-hit phenomenon or loss of heterozygosity, similar mutations could be found in patients with exposure to radiation therapy, chemotherapy, and voriconazole. ${ }^{16,17}$ Prolonged immunosuppression is shown to impair immune surveillance of dysplastic cells. ${ }^{18}$ There is evidence that specific immunosuppressive agents, such as systemic calcineurin inhibitors, may heighten NMSC risk..$^{19,20}$ These cumulative effects could result in development and uncontrolled growth of NMSC in children and young adults.

Inherent vulnerability to sunburn could also play a role in development of NMSC in this population, as most of our patients with iatrogenic risk factors were white and classified as either Fitzpatrick skin phototype I or II (if documented).

We identified gaps in care for children and young adults with NMSC. There was a significant delay in initial diagnosis in both patients with SCC and BCC, with an overall mean of 948 days from time of lesion onset to time of diagnosis. These data correspond to prior studies from the 1960 to 1970 s that showed a delay in diagnosis of 3 months to 6.1 years in children with BCC. ${ }^{21,22}$ Initial misdiagnosis in $36 \%$ of patients suggests that education regarding risk factors and monitoring of NMSC is needed for patients and medical providers.

Although most of our patients developed subsequent NMSC after their initial diagnosis, the majority of cases were treated successfully with surgical excision, without recurrence or spread of disease. This suggests that interventions in children and young adults that involve prevention of subsequent disease may be most impactful.

Limitations to our study included the small number of cases despite a 21-year time span. Retrospective design limited our study to what was available in the medical records. Given the rarity of NMSC in children and young adults, a multi-institutional study is needed to confirm and expand on our findings. Overlap of predisposing conditions and iatrogenic risk factors may have confounded our data. Lastly, although our data suggested associations between SCC and prolonged immunosuppression, and BCC with radiation therapy, the exact pathogenesis of these processes could not be determined. Future tissue analysis of tumor suppressor and oncogene expression may help refine our understanding of NMSC.

Physicians should be aware of risk factors that predispose a child or young adult to skin cancer so that appropriate counseling and monitoring along with early recognition and treatment can be provided. 


\section{REFERENCES}

1. Holman JD, Dyer JA. Genodermatoses with malignant potential. Curr Opin Pediatr. 2007;19:446-454.

2. Rork JF, Margossian SP, Nambudiri VE, et al. Nonmelanoma skin cancer in childhood after hematopoietic stem cell transplant: a report of 4 cases. J Pediatr Hematol Oncol. 2014;36:224-227.

3. Cowen EW, Nguyen JC, Miller DD, et al. Chronic phototoxicity and aggressive squamous cell carcinoma of the skin in children and adults during treatment with voriconazole. J Am Acad Dermatol. 2010;62:31-37.

4. Unal S, Cetin M, Gumruk F. Basal cell carcinoma after treatment of childhood acute lymphoblastic leukemia and concise review of the literature. Pediatr Dermatol. 2015;32:e82-e85.

5. Watt TC, Inskip PD, Stratton K, et al. Radiation-related risk of basal cell carcinoma: a report from the Childhood Cancer Survivor Study. J Natl Cancer Inst. 2012;104:1240-1250.

6. Leisenring W, Friedman DL, Flowers ME, et al. Nonmelanoma skin and mucosal cancers after hematopoietic cell transplantation. J Clin Oncol. 2006;24:1119-1126.

7. Euvrard S, Kanitakis J, Claudy A. Skin cancers after organ transplantation. N Engl J Med. 2003;348:1681-1691.

8. Rosen H, Schmidt B, Lam HP, et al. Management of nevus sebaceous and the risk of basal cell carcinoma: an 18-year review. Pediatr Dermatol. 2009;26:676-681.

9. Gorlin RJ, Vickers RA, Kellen E, et al. Multiple basal-cell nevi syndrome. Cancer. 1965;18:89-104.

10. Beogo R, Andonaba J, Bouletreau P, et al. Xeroderma pigmentosum révélé par des carcinomes épidermoïdes multiples de la face chez un enfant. Rev Stomatol Chir Maxillofac. 2012;113:50-52.

11. Jamnadas B, Agarwal R, Caddy CM. A rare case of SCC in a young patient with incontinentia pigmenti. J Plast Reconstr Aesthet Surg. 2008;61:973-974.
12. Comstock J, Hansen RC, Korc A. Basal cell carcinoma in a 12-year-old boy. Pediatrics. 1990;86:460-463.

13. Efron PA, Chen MK, Glavin FL, et al. Pediatric basal cell carcinoma: case reports and literature review. J Pediatr Surg. 2008;43:2277-2280.

14. Yazici B, Cicek S, Adim SB. Eyelid basal cell carcinoma in a healthy child. J Pediatr Ophthalmol Strabismus. 2014;51 Online: e82-e84.

15. Schwartz JL, Kopecky KJ, Mathes RW, et al. Basal cell skin cancer after total-body irradiation and hematopoietic cell transplantation. Radiat Res. 2009;171:155-163.

16. Fan $H$, Oro $A E$, Scott $M P$, et al. Induction of basal cell carcinoma features in transgenic human skin expressing Sonic Hedgehog. Nat Med. 1997;3:788-792.

17. Brown VL, Harwood CA, Crook T, et al. p16INK4a and p14ARF tumor suppressor genes are commonly inactivated in cutaneous squamous cell carcinoma. J Invest Dermatol. 2004;122: 1284-1292.

18. Muehleisen B, Jiang SB, Gladsjo JA, et al. Distinct innate immune gene expression profiles in non-melanoma skin cancer of immunocompetent and immunosuppressed patients. PLoS One. 2012;7:e40754.

19. Kuschal C, Thoms KM, Schubert S, et al. Skin cancer in organ transplant recipients: effects of immunosuppressive medications on DNA repair. Exp Dermatol. 2012;21:2-6.

20. Wheless L, Jacks S, Mooneyham Potter KA, et al. Skin cancer in organ transplant recipients: more than the immune system. J Am Acad Dermatol. 2014;71:359-365.

21. Murray JE, Cannon B. Basal-cell cancer in children and young adults. N Engl J Med. 1960;262:440-443.

22. Milstone EB, Helwig EB. Basal cell carcinoma in children. Arch Dermatol. 1973;108:523-527. 